bouwwerken, maar ook op het bouwen van bouwwerken in strijd met de planologische regelgeving, maar deze uitleg van het begrip gebruik ziet niet op het bouwen als bedoeld in artikel 2.1, eerste lid, aanhef en onder a, van de Wabo, maar uitsluitend op het bepaalde onder $\mathrm{c}$.

Reeds daarom komt de aangevallen uitspraak in zoverre voor vernietiging in aanmerking. Hetgeen [appellante] voor het overige heeft aangevoerd behoeft geen bespreking.

Het betoog slaagt.

7. Het hoger beroep is gegrond. De aangevallen uitspraak dient te worden vernietigd. Doende hetgeen de rechtbank zou behoren te doen, zal de Afdeling het beroep tegen de besluiten van 22 november 2013 van het college alsnog gegrond verklaren. Die besluiten komen wegens strijd met artikel 2.1, eerste lid, aanhef en onder a, van de Wabo en artikel 3:4, tweede lid, van de Algemene wet bestuursrecht (hierna: de Awb) voor vernietiging in aanmerking in verband met het handhavend optreden tegen het bouwen van het zomerhuisje zonder omgevingsvergunning onderscheidenlijk tegen het (laten) gebruiken van het zomerhuisje als slaapruimte en nachtverblijf. De Afdeling zal met toepassing van art 8:72, derde lid, aanhef en onder b, van de Awb zelf in de zaak voorzien door de besluiten van 14 mei 2013 te herroepen en het verzoek van [belanghebbende] om handhavend op te treden af te wijzen. De Afdeling ziet daartoe aanleiding op grond van het volgende.

De grondslag voor handhavend optreden tegen het bouwen van het zomerhuisje kan ook niet gelegen zijn in artikel 2.1, eerste lid, aanhef en onder c, van de Wabo. Het zomerhuisje is in strijd met het bestemmingsplan omdat het niet past binnen de in artikel 21.1 van de planregels gegeven omschrijving van de op het perceel rustende bestemming "Wonen". Om die reden is het eveneens in strijd met artikel 21.2.1, onder 2, van de planregels waarin is bepaald dat er uitsluitend mag worden gebouwd ten behoeve van de in de bestemmingsomschrijving aangegeven doeleinden. Als gevolg van de inwerkingtreding van artikel 2.1, eerste lid, aanhef en onder c, van de Wabo op 1 oktober 2010 en de daarover gevormde jurisprudentie van de Afdeling dat het begrip gebruiken als bedoeld in die bepaling ook betrekking heeft op het bouwen van bouwwerken in strijd met een bestemmingsplan (uitspraak van 26 oktober 2011, in zaak nr. 201103159/1/H1), is voor het bouwen van een bouwwerk in strijd met de regels van een bestemmingsplan een omgevingsvergunning als bedoeld in artikel 2.1, eerste lid, aanhef en onder c, van de Wabo vereist. Echter, op het moment dat het zomerhuisje op het perceel werd opgericht, van welk bouwwerk vast staat dat het sinds 1963 op het perceel aanwezig is, gold het verbod op het gebruiken in de zin van bouwen in strijd met de regels van een bestemmingsplan nog niet, noch een daarmee gelijk te stellen verbodsbepaling. Het gebruiken in de zin van bouwen in strijd met regels van een bestemmingsplan is eerst met de inwerkingtreding van artikel 2.1, eerste lid, aanhef en onder c, van de Wabo op 1 oktober 2010 verboden geworden. Nu het zomerhuisje is gebouwd voor die datum, is geen sprake van een overtreding van artikel 2.1, eerste lid, aanhef en onder $\mathrm{c}$, van de Wabo. Evenmin bestaat grond voor het oordeel dat [appellante] het zomerhuisje in strijd met artikel 2.3a, eerste lid, van de Wabo zonder de daarvoor vereiste omgevingsvergunning als bedoeld in artikel 2.1, eerste lid, aanhef en onder c, van de Wabo in stand laat, nu dit verbod alleen geldt als het gaat om een bouwactiviteit waarvoor op grond van artikel 2.1, eerste lid, aanhef en onder a, van de Wabo een omgevingsvergunning is vereist. Artikel 2.3a, eerste lid, van de Wabo heeft geen betrekking op het gebruiken van gronden of bouwwerken in strijd met een bestemmingsplan, zoals bedoeld in artikel 2.1, eerste lid, aanhef en onder c, van de Wabo (vergelijk de uitspraken van de Afdeling van 3 juni 2015 in zaaknr. 201405411/1/A1 en 19 augustus 2015, in zaaknr. 201409484/1/A1).

De Afdeling zal tot slot bepalen dat deze uitspraak in de plaats treedt van de vernietigde besluiten.

$$
16-23
$$

\section{ABRvS 2 december 2015, nr. 201503151/1/A1 (Sluis/weigering omgevingsvergunning) (ECLI:NL:RVS:2015:3695)}

Weliswaar ziet de omgevingsvergunning slechts op de wijziging van het gebruik van een bestaand pand, met een herinrichting en een aanpassing van de gevel, zodat de gevolgen voor de ruimtelijke uitstraling van verlening van de omgevingsvergunning voor 
het project, indien dat niet uitvoerbaar blijkt, beperkt zullen zijn, maar dat betekent niet dat de vraag naar de uitvoerbaarheid van het project geen ruimtelijk belang is. De omstandigheid dat artikel 3.1.6 van het Bro niet van toepassing is op verlening van een omgevingsvergunning met toepassing van artikel 2.12, eerste lid, aanhef en onderdeel a, onder $2^{\circ}$, van de Wabo, betekent voorts niet dat het college de uitvoerbaarheid van het project niet bij de aan het besluit ten grondslag liggende beoordeling mag betrekken. Ingevolge laatstgenoemde bepaling dient het college bij zijn beslissing op de aanvraag te beoordelen of de activiteit niet in strijd is met een goede ruimtelijke ordening. Daarbij kan het de uitvoerbaarheid van het project in aanmerking nemen. De enkele, ten tijde van het nemen van het besluit op bezwaar nog niet onherroepelijke, weigering van de voor de exploitatie van de speelautomatenhal benodigde vergunning is evenwel onvoldoende voor de conclusie dat de omgevingsvergunning niet uitvoerbaar is.

artikel 2.12 lid 1 aanhef en onderdeel a onder $2^{\circ}$ Wabo

artikel 4 lid 9 Bijlage II Bor

artikel 3.1.6 Bro

artikel 3:2 lid 1 Awb

artikel 7:12 lid 1 Awb

1. Het gebruik van het pand als speelautomatenhal is in strijd met de ingevolge het bestemmingsplan "Kom Sluis" op de desbetreffende gronden rustende bestemming "Centrumvoorzieningen".

3. Het college heeft geweigerd voor het gebruik van het pand als speelautomatenhal een omgevingsvergunning met toepassing van artikel 2.12, eerste lid, aanhef en onder a, onder $2^{\circ}$, van de Wabo in samenhang gelezen met artikel 4, negende lid, van bijlage II van het Bor te verlenen. Het college heeft aan de weigering ten grondslag gelegd dat het project niet uitvoerbaar zal zijn vanwege het ontbreken van een exploitatievergunning, die op grond van de Verordening inzake kansspelautomaten en speelautomatenhallen 2010 (hierna: de Verordening) is vereist om een dergelijke activiteiten te ontplooien.

Bij het in bezwaar gehandhaafde besluit van 11 juni 2014 heeft de burgemeester van Sluis de aanvraag van RPZ om exploitatievergunning afgewezen omdat het maximaal aantal af te geven vergunningen voor speelautomatenhalen was verleend, nadat de burgemeester bij besluit van dezelfde datum exploitatievergunning had verleend aan Casino Sluis N.V. De burgemeester heeft op basis van een vergelijking van de twee aanvragen aan zijn besluitvorming ten grondslag gelegd dat Casino Sluis het beste voldoet. Volgens het college kan RPZ pas in april 2018 mogelijk weer over een exploitatievergunning beschikken.

4. Het college betoogt dat de rechtbank ten onrechte heeft overwogen dat het college de aanvraag had moeten toetsen aan het in artikel 15 van de Beleidsregels opgenomen algemene afwegingskader en dat de vraag of een project uitvoerbaar is daarvan geen deel uitmaakt, zodat het college de omgevingsvergunning niet kon weigeren vanwege het feit dat het project niet uitvoerbaar is. Het college voert hiertoe aan dat uitvoerbaarheid van het project weliswaar niet is vermeld in artikel 15 van de Beleidsregels, maar dat dit niet betekent dat de Beleidsregels geen ruimte bieden voor de gemaakte afweging. Voorts voert het college aan dat het enkele feit dat artikel 3.1.6, eerste lid, aanhef en onder $f$, van het Besluit ruimtelijke ordening (hierna: het Bro) in dit geval niet van toepassing is, niet meebrengt dat de omgevingsvergunning niet geweigerd mag worden op de grond dat onvoldoende aannemelijk is dat het project uitvoerbaar is.

4.1. Dat op grond van artikel 15 van de Beleidsregels slechts omgevingsvergunning voor het afwijken van het bestemmingsplan kan worden verleend na toetsing aan de in dat artikel vermelde criteria, betekent niet dat die omgevingsvergunning moet worden verleend indien die criteria geen beletsel opwerpen. Artikel 17 van de Beleidsregels biedt het college de ruimte om gemotiveerd medewerking door af te wijken van het bestemmingsplan te weigeren, ook indien het project voldoet aan de in artikel 15 van de Beleidsregels vermelde criteria voldoet. Geen grond bestaat dan ook voor het oordeel dat het college de omgevingsvergunning niet mag weigeren om redenen die niet in het algemeen afwegingskader van artikel 15 van de Beleidsregels zijn vermeld.

4.2. De rechtbank heeft het besluit op bezwaar evenwel, zij het op andere gronden, terecht vernietigd. De Afdeling overweegt daartoe het volgende. 
4.3. Weliswaar ziet de omgevingsvergunning slechts op de wijziging van het gebruik van een bestaand pand, met een herinrichting en een aanpassing van de gevel, zodat de gevolgen voor de ruimtelijke uitstraling van verlening van de omgevingsvergunning voor het project, indien dat niet uitvoerbaar blijkt, beperkt zullen zijn, maar dat betekent niet dat de vraag naar de uitvoerbaarheid van het project geen ruimtelijk belang is, zoals RPZ stelt. De omstandigheid dat artikel 3.1.6 van het Bro niet van toepassing is op verlening van een omgevingsvergunning met toepassing van artikel 2.12, eerste lid, aanhef en onder a, onder $2^{\circ}$, van de Wabo, betekent voorts niet dat het college de uitvoerbaarheid van het project niet bij de aan het besluit ten grondslag liggende beoordeling mag betrekken. Ingevolge laatstgenoemde bepaling dient het college bij zijn beslissing op de aanvraag te beoordelen of de activiteit niet in strijd is met een goede ruimtelijke ordening. Daarbij kan het de uitvoerbaarheid van het project in aanmerking nemen. De enkele, ten tijde van het nemen van het besluit op bezwaar nog niet onherroepelijke weigering van de voor de exploitatie van de speelautomatenhal benodigde vergunning is evenwel onvoldoende voor de conclusie dat de omgevingsvergunning niet uitvoerbaar is. Bij zijn beoordeling of het project vanuit het oogpunt van een goede ruimtelijke ordening al dan niet aanvaardbaar is, kon het college derhalve niet volstaan met de vaststelling dat een exploitatievergunning ontbreekt. Nu het college bij de beoordeling van de aanvraag om omgevingsvergunning geen eigen gemotiveerde ruimtelijke afweging van de bij het besluit betrokken belangen heeft gemaakt, berust het besluit op een onvoldoende draagkrachtige motivering en is het besluit niet met de vereiste zorgvuldigheid tot stand gekomen. Gelet hierop dient het besluit te worden vernietigd wegens strijd met de artikelen $3: 2$ en 7:12, eerste lid, van de Algemene wet bestuursrecht. Het college zal een nieuw besluit dienen te nemen met inachtneming van hetgeen in deze uitspraak is overwogen.

Het betoog faalt.

\section{Annotatie}

1. De Afdelingsuitspraak van 2 december 2015 (ECLI:NL:RVS:2015:3695) over het besluit van het college van $B \& W$ van Sluis om een omgevingsvergunning voor het gebruik van een pand als speelautomatenhal te weigeren, nodigt uit tot het maken van een kanttekening bij de door de gemeente Sluis gehanteerde beleidsregels en tot een doorkijkje naar de Omgevingswet (Ow).

2. Veel gemeenten hebben beleidsregels vastgesteld ter nadere afbakening van de bevoegdheid om met toepassing van artikel 2.12 lid 1 onderdeel a onder $2^{\circ}$ van de Wabo jo. artikel 4 van bijlage II van het Bor een omgevingsvergunning te verlenen voor gebruik dat afwijkt van het bestemmingsplan (met ingang van 9 september 2015 (Stb. 2015, 323) is onderdeel 9 van artikel 4 van bijlage ॥ overigens uitgebreid in die zin dat toepassing buiten de bebouwde kom ook kan ten behoeve van de opvang van asielzoekers of andere categorieën vreemdelingen, maar dat is voor de onderhavige zaak verder niet relevant). Het vaststellen van dit soort beleidsregels is algemeen aanvaard (o.a. ABRvS 27 augustus 2014, ECLI:NL:RVS: 2014:3234 en ABRvS 2 december 2015, ECLI:NL: RVS:2015:3682). De keerzijde leek aanvankelijk dat als een initiatief niet past binnen de vastgestelde beleidsregels, toepassing van artikel 2.12 lid 1 onderdeel a van de Wabo in het geheel niet meer mogelijk zou zijn. In ABRvS 26 juni 2013, ECLI:NL:RVS:2013:58 werd namelijk geoordeeld (zie r.o. 3.2) dat de bevoegdheid om artikel $2.12 \mathrm{lid} 1$ onderdeel a onder $3^{\circ}$ van de Wabo in zo'n geval toe te passen, ontbreekt. Die consequentie werd (terecht) genuanceerd in ABRvS 24 december 2014, ECLI:NL:RVS: 2014:4667, waarin de Afdeling overweegt dat het bevoegd gezag niet gehouden is toepassing te geven aan artikel 2.12 lid 1 onderdeel a onder $3^{\circ}$ van de Wabo als het bouwplan binnen de reikwijdte van diezelfde bepaling onderdeel a onder $2^{\circ}$ valt, maar daarvoor, gelet op het ter zake gevoerde beleid, geen omgevingsvergunning kan worden verleend. Niet gehouden, maar dus wel bevoegd.

3. Het college van $B \& W$ van de gemeente Sluis heeft de genoemde Afdelingsuitspraak van 24 december 2014 niet nodig om ondanks de vastgestelde beleidsregels, een grote mate van discretionaire ruimte te houden ten aanzien van een aanvraag om omgevingsvergunning voor gebruik dat afwijkt van het bestemmingsplan. De beleidsregels bieden die ruimte namelijk zelf. Ik doel dan niet op de inherente afwijkingsbevoegdheid (art. 4:84 Awb) die in de beleidsregels van Sluis expliciet is gemaakt, maar op artikel 17 van de beleidsregels dat een algemeen geformuleerde mogelijkheid biedt om anders op een aanvraag om omgevingsvergunning te beslissen dan uit de beleidsregels voortvloeit. Dat geeft het bevoegd gezag veel beslisruimte. Tegelijkertijd leidt zo'n bepaling ertoe dat de 
mate van houvast die deze beleidsregels vergunningaanvragers en eventuele derdebelanghebbenden geven, naar mijn idee uitermate betrekkelijk is. Dat toetscriteria die niet in de beleidsregels worden genoemd - zoals de uitvoerbaarheid van een initiatief - toch bij de belangenafweging een rol mogen spelen, verbaast dan ook geenszins, gelet op artikel 17 van de beleidsregels.

4. Het enkele ontbreken van de benodigde exploitatievergunning is echter niet voldoende om de omgevingsvergunning te weigeren, aldus de Afdeling in r.o. 4.3. Vereist is een 'eigen gemotiveerde ruimtelijke afweging van de bij het besluit betrokken belangen'. Over de vraag hoe zo'n motivering er concreet uit moet zien en welke rol het ontbreken van een benodigde publiekrechtelijke toestemming daarin kan spelen, valt best het nodige te zeggen. Hoe dan ook kan de bedoelde motivering naar mijn mening evengoed als een 'goede ruimtelijke onderbouwing' worden geduid, hoewel dat begrip alleen in het derde onderdeel van artikel 2.12 lid 1 onderdeel a van de Wabo opduikt. Ik laat dat aspect hier verder rusten. Het gaat mij nu vooral om de vaststelling dat naar huidig recht voor één activiteit meerdere vergunningen nodig kunnen zijn met elk een eigen wettelijk afwegingskader (vgl. art. 3:4 lid 1 Awb). Deze meersporenproblematiek beoogt de Ow te beperken. Onder meer door de eis dat alle regels die van invloed zijn op de fysieke leefomgeving, op grond van artikel 4.1 en artikel $4.2 \mathrm{Ow}$ in het omgevingsplan moeten worden opgenomen. Dat soort regels mag na inwerkingtreding van de Ow niet meer in lokale verordeningen worden opgenomen (zie daarover o.a. A.E. Kneepkens, K. Krijt, B. Rademaker, Het omgevingsplan, TBR 2014/164). Een vergunningstelsel voor activiteiten die van invloed zijn op de fysieke leefomgeving náást het omgevingsvergunningstelsel van hoofdstuk 5 van de $0 \mathrm{w}$, is in dat systeem niet denkbaar (uiteraard afgezien van de omgevingsrechtelijke wetten of vergunningstelsels die niet integreren in de $\mathrm{Ow}$, zoals de Kernenergiewet). Toegespitst op de onderhavige zaak is dan de hamvraag of na inwerkingtreding van de $\mathrm{Ow}$, voor de onderhavige activiteit nog steeds een omgevingsvergunning én een exploitatievergunning vereist kunnen zijn. Ik denk het wel. Om twee redenen. De eerste is dat de regels omtrent het opstellen van speelautomaten weliswaar indirect van invloed kunnen zijn op de fysieke leefomgeving, maar het doel van dergelijke regels zal niet het benutten of het beschermen van de fysieke leefomgeving zijn. Aan de regels liggen sociaal-maatschappelijke argumenten, economische argumenten en argumenten die verband houden met de openbare orde ten grondslag. Voor dergelijke regels geldt ook na de inwerkingtreding van de $\mathrm{Ow}$ dat zij in een lokale verordening kunnen worden opgenomen, al dan niet gekoppeld aan een lokaal vergunningstelsel (bijv. een exploitatievergunning). Wat betreft regels die verband houden met de openbare orde, verdient vermelding dat - naar verluidt - ten departemente wordt overwogen om op grond van artikel 2.7 Ow bij AMvB te regelen dat dergelijke regels juist niet in het omgevingsplan mogen worden opgenomen. Dat houdt verband met de specifieke bevoegdheidsstructuur die de Gemeentewet ten aanzien van de handhaving van de openbare orde bevat en waarin de burgemeester een centrale rol heeft. Hoe een en ander uiteindelijk vorm wordt gegeven, zal uit de vier (naar verwachting medio 2016) te publiceren OwAMvB's moeten blijken.

Tonny Nijmeijer

\section{ABRvS 9 december 2015, nr. 201408171/1/A4 (Maasdriel/omgevingsvergunningen onbemand tankstation) (ECLI:NL:RVS:2015:3762)}

Aan TinQ Nederland B.V. zijn bij verschillende besluiten een omgevingsvergunning voor het veranderen van een onbemand tankstation en voor het verplaatsen en bouwen en aanleggen van ondergrondse brandstoftanks verleend.

De Afdeling merkt op dat ook indien de rechtbank terecht heeft geoordeeld dat op 5 juli 2012 van rechtswege een beschikking is gegeven, dit geen aanleiding kan zijn om, zoals de rechtbank heeft gedaan, het bezwaar uitsluitend op te vatten als gericht tegen die beschikking van rechtswege. Indien op 5 juli 2012 van rechtswege een beschikking is gegeven, was voor het alsnog nemen van een reëel besluit op de aanvraag weliswaar geen plaats meer, maar dat maakt, anders dan waarvan de rechtbank kennelijk is uitgegaan, niet dat het besluit van 26 juli 2012 in dat geval nietig is. Het bezwaar tegen het 